\title{
PROJETO NEOLIBERAL E JUSTIÇA DE TRANSIÇÃO: AS CONSEQUÊNCIAS DE SUAS INTERSECÇÕES PARA A CONCRETUDE DEMOCRÁTICA BRASILEIRA
}

\section{NEOLIBERAL PROJECT AND TRANSITIONAL JUSTICE: THE CONSEQUENCES OF THEIR INTERSECTIONS FOR THE BRAZILIAN DEMOCRATIC CONCRETENESS}

\section{PROYECTO NEOLIBERAL Y JUSTICIA DE TRANSICIÓN: LAS CONSECUENCIAS DE SUS INTERSECCIONES PARA EL CONCRETO DEMOCRÁTICO BRASILEÑO}

\section{Resumo}

Daniel Wanderley Caliman ${ }^{1}$

O trabalho analisa o processo de transição da forma de Estado ditatorial, implantada durante o regime cívico-militar no Brasil (1964-1985), para a forma de um Estado Democrático de Direito embasado pelo princípio dos direitos humanos. Pela ótica da Justiça de Transição, busca-se compreender as nuances de seu uso no Brasil e sua real capacidade de intervenção no plano político-institucional. Percebendo a transversalidade da questão de disputa por hegemonia e suas consequências, como a organização de blocos no poder para implementação de projetos políticoeconômicos, o artigo trata de identificar o papel do neoliberalismo nesse processo transicional, da ditadura para a democracia, identificando as perspectivas teóricas acerca da democracia, os direitos e as atribuições do Estado. Identifica-se que as intersecções entre neoliberalismo e Justiça de Transição potencializam uma "excepcionalidade continuada" no Estado brasileiro, fazendo com que se mantenham, ainda que sob a forma de Estado Democrático de Direito, estruturas antidemocráticas.

Palavras-chave: Justiça transicional. Neoliberalismo. Democracia. Direitos Humanos. Hegemonia.

\begin{abstract}
This paper analyzes the transition process from the dictatorial State, implanted during the civil-military regime in Brazil (1964-1985), to the democratic State based on the principles of human rights. It does that through the lenses of transitional justice, seeking to understand the nuances of its use in Brazil and its real intervention capability into the political-institutional framework. Noticing the transversality of the hegemony dispute in this issue and its consequences, as is the organization of blocks in power to implement a political-economical project, the paper ensures to identify the role of neoliberalism in this transitional process, from dictatorship to democracy, underlining for such, the theoretical perspectives of this project on democracy, rights and State assignments. Through this effort, it is identified that the intersections between neoliberalism and transitional justice are due to potentialize a "continued exceptional State" within the brazilian State, which makes undemocratic structures still present in a democratic form of State.
\end{abstract}

Key-words: Transitional justice. Neoliberalism. Democracy. Human Rights. Hegemony.

\section{Resumen}

El trabajo analiza el proceso de transición de la forma de Estado dictatorial, implantada durante el régimen cívicomilitar en Brasil (1964-1985), a la forma de Estado Democrático de Derecho basado en el principio de derechos humanos. Desde la perspectiva de la Justicia Transicional, buscamos comprender los matices de su uso en Brasil y su capacidad real de intervención a nivel político-institucional. Al darse cuenta de la transversalidad del tema de la disputa por la hegemonía y sus consecuencias, como la organización de bloques en el poder para implementar proyectos político-económicos, el artículo trata de identificar el papel del neoliberalismo en este proceso de transición, de la dictadura a la democracia, identificando las perspectivas visiones teóricas sobre la democracia, los derechos y atribuciones del Estado. Se identifica que las intersecciones entre neoliberalismo y Justicia Transicional potencian la "excepcionalidad continuada" en el Estado brasileño, permitiendo mantener, incluso en la forma de un Estado Democrático de Derecho, estructuras antidemocráticas.

Palabras clave: Justicia transicional. Neoliberalismo. Democracia. Derechos humanos. Hegemonía.

${ }^{1}$ Graduado em Relações Internacionais pela UFU. Foi coordenador geral do DCE-UFU e bolsista do projeto Curau, Subcomissão Regional da Verdade. Pesquisa a construção de hegemonia, Estado e democracia, internacionalismo partidário e político em conexões com políticas públicas. danielwanderley0@gmail.com 


\section{INTRODUÇÃO}

Através da observação do processo histórico brasileiro, torna-se nítida uma "excepcionalidade continuada". Esse termo busca expressar uma relação em que os momentos de pactuações políticas em torno de cartas constitucionais, que garantam direitos sociais, políticos, econômicos e liberdades, se fazem menos comuns do que os chamados "períodos de exceção" (GOMES; MATOS, 2017), de forma tal que a compreensão das passagens democráticas deve ser sempre analisadas sob ótica criteriosa e atenta aos muitos fatores que permeiam a sua constituição. "Período de exceção" expressa, então, um momento de restrição de direitos e concentração excessiva de poderes, no qual se dissipa a distinção entre Estado de Direito e Estado Absolutista (GOMES; MATOS, 2017). Por isso pretende esse artigo analisar o período de vigência do pacto de variadas forças da sociedade brasileira em torno da Constituição de 1988 (CF88) através da perspectiva da Justiça de Transição, compreendendo seu processo na passagem do período de ditadura cívico-militar (1964-1985) para o Estado Democrático de Direito que buscou-se consolidar desde então.

Entender esse processo passa, impreterivelmente, pela disposição dos fatores políticos e econômicos que atravessam a questão. Dentre os quais focar-se-á o trabalho na relevância do projeto neoliberal, implantado no Brasil após a promulgação da CF88, no enfraquecimento das próprias instituições advindas dessa Constituição, bloqueando instrumentos chaves para sua consolidação, principalmente aqueles tangenciados por dispositivos de direitos sociais, políticos, econômicos e direitos humanos no geral (CANDIOTTO, 2012) e dificultando a implementação adequada de uma Justiça de Transição que permitisse a superação das estruturas sociais, econômicas e políticas do "período de exceção". Esse seria um passo elementar na estruturação do Estado Democrático de Direito e, principalmente, para dar concretude à democracia nascente da nova pactuação política.

Uma Constituição percebida, então, como consequência de uma pactuação política, dá forma a uma unidade em torno de preceitos comuns que orientem a ação dos membros de determinada sociedade (SCHMITT, 1996). Isso não quer dizer que não haja espaço dentro de um Estado Constitucional, que se construa sob a forma democrática, para diferentes interpretações e projetos políticos, desde que orientados pelos dispositivos pactuados. Têm-se nesse próprio fator, a dinâmica essencial pela disputa da hegemonia do Estado, considerando suas várias instituições, para a qual, principalmente no tocante ao governo, organizam-se blocos 
no poder $^{2}$ para consolidar um projeto político e econômico que garanta a efetiva aplicação da interpretação dos grupos organizados naquele bloco sobre o pacto efetuado previamente (POULANTZAS, 1977). Desde 1989, com a eleição de Fernando Collor de Mello, potencializando-se entre 1995-2002, nas administrações Fernando Henrique Cardoso (FHC), com um hiato entre 2003 e 2016 nas gestões petistas, consolidou-se como fração de classe hegemônica no bloco no poder do Brasil a burguesia compradora, que é aquela sem bases de acumulação própria (ou seja, não ligada à atividade produtiva), acompanhando de forma dependente os movimentos do grande capital financeiro internacional, controlado pelos centros econômicos mundiais (BERRINGER, 2014) e organizados no bloco histórico ${ }^{3}$ neoliberal que se dá, também, através da confluência de blocos no poder em variados Estados.

Esse bloco no poder que deu sustentação ao projeto neoliberal no período imediato após a promulgação da CF88, na visão apresentado por este trabalho, serviu como potencializador das dificuldades de implementação adequada de uma Justiça de Transição no Brasil. A título de elucidação, a Justiça de Transição pode ser definida como o processo, político e judicial, através do qual se assegura a responsabilização por desrespeitos aos direitos humanos em regimes autoritários, como forma de impedir novas violações (SALES, 2016). Apesar de alguns elementos para essa transição terem sido incluídos na gestão de FHC, através da Lei da Comissão Especial para Mortos e Desaparecidos Políticos de 1995 ou ainda antes, quando Fernando Collor permitiu a abertura dos arquivos do DOPS (órgão repressor da ditadura) de São Paulo e Rio de Janeiro (CNV, 2012) é apenas em 2012, 28 anos depois do início do processo de transição da ditadura para a democracia, que se instala, acompanhando finalmente o movimento internacional de ruptura com períodos de exceção, uma comissão responsável por investigar de forma sistemática os crimes cometidos durante a ditadura cívico-militar: a Comissão Nacional da Verdade (CNV).

A instalação da CNV seria também expressão da reconfiguração do bloco no poder, naquele momento conduzido pela burguesia interna (aquela que tem bases de investimentos produtivos, como fábricas) em aliança com as classes trabalhadoras urbanas e rurais (BERRINGER, 2014), incidindo na disputa hegemônica pelo Estado e redirecionando sua capacidade de intervenção.

Logo, a alternância entre as duas formas de Estado, ditatorial e democrático, se daria em meio ao cenário de acordos possíveis para essa transição, assim como a permeação da disputa

\footnotetext{
${ }^{2}$ Alinhamento entre classes e frações de classe no intuito de exercício do poder e implementação de um projeto (POULANTZAS, 1977)

${ }^{3}$ Síntese entre a estrutura (aspecto material e econômico) e a superestrutura (aspecto moral, cultural, educacional, etc..) organizado e liderado por uma classe no sentido de hegemonia sobre as demais (GRAMSCI, 1985)
} 
hegemônica pela implementação de um projeto político-econômico. Do primeiro cenário, a Lei de Anistia de 1979 é um importante fator para compreensão mais ampla das barreiras institucionais à implementação de uma Justiça de Transição no Brasil. Seu caráter "amplo, geral e irrestrito", como entoava o mote à época, impossibilitou a devida realocação de pessoal e reestruturação das instituições, como ver-se-á mais profundamente ao longo do artigo.

Com o intuito de sistematizar a discussão aqui apresentada, o trabalho se dividirá em três seções, em que se buscará, através do acesso à bibliografia já existente, alinhar algumas dessas questões. A primeira sessão trata da Justiça de Transição no processo de mudança da ditadura para a democracia, considerando seus pactos, movimentos e consolidações. A segunda fala sobre a implementação de Justiça de Transição no Brasil, suas formas, fazendo algumas comparações internacionais com o movimento internacional de desenvolvimento de comissões da verdade e a sua função no Brasil. Na terceira sessão, apresenta-se a discussão sobre o papel do neoliberalismo na efetiva diminuição da concretude da democracia no Brasil, contextualizando o processo pelo qual torna-se hegemônico o neoliberalismo no cenário internacional e no Brasil. Por fim, espera-se abstrair da discussão algumas conclusões e também questionamentos possíveis para o entendimento global dos aspectos apresentados no artigo.

\section{FOI POSSÍVEL DESORGANIZAR POLÍTICAE INSTITUCIONALMENTE A DITADURA CÍVICO- MILITAR?}

Partindo de um questionamento, torna-se mais potente a atividade de descrição do processo de transição do "período de exceção" que regeu o Brasil entre 1964-1985 para o Estado Democrático de Direito regido pela CF88: Foi possível desorganizar política e institucionalmente a ditadura cívico-militar? E pode-se levar o questionamento adiante: quais mecanismos dificultaram ou impediram sua superação?

Com objetivo pedagógico expõe-se aqui, primeiramente, o conceito de anistia: uma relação etimológica ao esquecimento, um perdão qualificado pelo direito (MOREIRA, 2019). A partir dessa conceituação, afirma-se que a redemocratização no Brasil se guiou sob o signo de uma anistia ambígua, que representou tanto as lutas da sociedade civil pela abertura do regime, como o empenho dos agentes da ditadura em garantir uma transição que não os responsabilizasse pelos crimes que praticaram (SILVA FILHO, 2018). Essa ambiguidade garante a transição lenta e gradual, sem rupturas, que tinha por objetivo, da parte dos controladores do regime, a manutenção da estrutura institucional que negava, à cabo, elementos básicos dos 
direitos humanos, como direitos políticos concretos, liberdades individuais e garantias constitucionais da observação, pelo Estado, aos direitos econômicos e políticos.

Ora, se os direitos humanos são concebidos em sua própria definição como uma utopia minimalista, que cumpre a responsabilidade de promover o diálogo entre personagens antagônicos (MOYN, 2010) e a oposição entre uma ditadura de caráter militar e o movimento civil por transformação democrática se dá principalmente nesse campo, a incapacidade de reunir antagonismos em torno de direitos básicos, a principal tarefa na transição de um período com aquele caráter para a democracia é a estruturação normativa e institucional em torno desses mesmos direitos. É então que se vislumbra a Justiça de Transição como método para aplicação devida de direitos humanos (HOLLANDA, 2018), através de uma "desconstrução construtiva", ou seja, o processo de desmantelar o arcabouço de mecanismos que levavam ao sistemático desrespeito aos direitos humanos, na busca por construir um novo que se erga justamente com base neles.

É notável de atenção, no entanto, que a terminologia “Justiça de Transição" não constava nem no campo teórico do Direito, nem no jargão político da época de superação dos regimes autoritários na América Latina (que se deu, em grande parte, nos anos 1980), pois o termo toma corpo apenas em 1992, a partir das análises de Ruti Teitel. Apesar de já haver preocupação com o tema da transição nos tribunais de Nuremberg (1945-1946) e de Tóquio (1946-1948), ela não se dava de forma sistemática (HOLLANDA, 2018), fazendo com que à época das transições na América Latina ainda não houvesse acúmulo suficiente sobre essa temática. Em específico na região, esse fato pode levar à inferência de que não existia ainda, pelo movimento democrático, compreensão do caráter vital de um processo que garantisse não apenas a punição aos infratores de direitos humanos e reparação aos atingidos, mas também de criação de novas narrativas a partir da investigação e exposição da verdade omitida pelos regimes.

Atendo-se a esse processo no Brasil, é possível perceber que a ambiguidade do processo transitório, como descrito acima, se dá, inicialmente, com base na Lei de Anistia de 1979, $\mathrm{N}^{\circ}$ 6.683, que seria resultado de um movimento duplo: por parte da sociedade civil, de desgaste da ditadura e por parte do regime, de distensão do mesmo. O mote impulsionador da movimentação popular seria a realização de uma anistia "ampla, geral e irrestrita". Essa amplitude seria então utilizada pelos militares para blindar seu corpo contra futuras punições que pudessem decorrer de sua derrota política, na prática impedindo o desmantelamento das estruturas legislativas, jurídicas, militares e até mesmo políticas que deram sobrevida ao regime por 21 anos. Sobre isso Silva Filho (2018) indicou: 
[...] o aspecto autoritário e reacionário da anistia refletiu-se no esquecimento institucional dos crimes contra a humanidade praticados e sua necessária responsabilização. Tal bloqueio, devidamente afirmado pelo Poder Judiciário em todas as tentativas que foram feitas de investigar e responsabilizar esses crimes, também favoreceu a ausência de reformas institucionais que buscassem esclarecer a participação dos poderes constituídos no regime ditatorial, bem como de processos de responsabilização administrativa e judicial sobre os agentes e funcionários públicos que facilitaram ou praticaram diretamente tais crimes (SILVA FILHO, 2018, p. 1287).

Com isso, membros da estrutura militar, jurídica, legislativa e política que formaram parte indispensável para a manutenção do regime ditatorial, mantiveram seus postos, impedindo de forma concreta, a superação das estruturas que deram sustentação à forma de Estado "ditaduta militar", permitindo apenas com que a nova forma construída se colocasse de forma sintética. Não se quer dizer aqui que a derrota política da ditadura cívico-militar não trouxe nenhuma nova estrutura permeável às manifestações populares e ao voto universal, mas que na verdade estas se encontravam constrangidas por uma institucionalidade carregada de mecanismos (e agentes) pouco afeitos às nunces democráticas (SILVA FILHO, 2018).

Além disso, a Lei de Anistia seria confirmada pela Emenda Constitucional N²6/1985, sugerindo que a Constituinte, fruto mesmo do processo de movimentação popular em torno da anistia, que passaria pelas "Diretas Já" e desembocaria por fim nela, não poderia revisar seu conteúdo. A nova Constituição, apesar de não endossar a anistia, é contraditória ao não suprimíla expressamente e a Comissão de Anistia dela advinda tem por função apenas a reparação de danos que, desarticulada da punição, não cumpre o papel de desfazer as estruturas do Estado ditatorial. Uma das grandes razões para a necessidade de um processo investigativo é que, diferente de outras ditaduras no continente, a ditadura brasileira contou com uma participação estreita do sistema judicial, logo, uma vez que não apenas as estruturas políticas tomaram parte no regime, para além de executivo e legislativo, deveria passar por reformulações também o judiciário o que, diante do caráter da Lei de Anistia e sua confirmação, não foi possível (SCHINKE, 2016).

Esses fatores contribuíram para um ambiente de permissividade a uma sistemática infração à estrutura de direitos humanos, criada pela CF88, e igualmente para a fragilidade de possibilidades de reformas econômicas progressistas, haja vista o constrangimento criado pelas instituições formais do Estado brasileiro, ainda que em sua forma democrática, uma vez que carregavam-se as digitais da institucionalidade sob a forma "ditadura militar".

Ruti Teitel (2011) descreve justiça transicional como aquela que se associa a períodos de mudança política, objetivando dar respostas jurídicas aos atos criminosos cometidos por regimes de exceção no passado. Ao partir-se desse preceito, observa-se que a possibilidade de aplicação de uma Justiça de Transição no Brasil foi bloqueada, então, pelos termos da anistia, assim como 
a sua confirmação pela Emenda Constitucional $N^{\circ} 26 / 1985$ (que na prática tolhia a soberania da Constituinte), uma vez que impossibilitava a responsabilização jurídica dos partícipes de crimes contra direitos humanos durante a ditadura cívico-militar.

Para além da seara punitiva, a Justiça de Transição se encarrega igualmente de um processo mais criterioso e, portanto, mais permeado pela dinâmica das disputas políticas por construção de hegemonia: a construção de novas narrativas acerca dos fatos ocorridos no passado. Essa empreitada só se apresenta numa segunda fase do que é caracterizado como justiça transicional (termo aqui utilizado como sinônimo de Justiça de Transição), nos últimos 25 anos do século XX. A partir dela surge uma dicotomia entre verdade e justiça, que leva a um movimento de criação de Comissões da Verdade, iniciado na Argentina. Apesar de naquele país o intuito de sua comissão não ter sido voltado para a conciliação, esse foi o teor adotado internacionalmente, em especial, se torna como modelo investigativo a África do Sul pósApartheid (TEITEL, 2011).

Como ver-se-á na próxima seção desse artigo, o processo de recondução de narrativas através de uma Comissão da Verdade só se concretizará no Brasil em 2012, sob o governo de Dilma Rousseff (2011-2016), que outrora houvera sido presa e torturada enquanto oposição à ditadura brasileira.

Surge então um novo questionamento: quais foram, ao longo da consolidação democrática no Brasil, os mecanismos, instrumentos e construções em torno de superação das estruturas antidemocráticas?

\section{O CAMINHO DA JUSTIÇA DE TRANSIÇÃO NO BRASIL}

Desvincular os direitos humanos do exercício do poder político é uma tarefa ilusória. Quando se associa a Justiça de Transição ao caminho pelo qual se inserem esses direitos como base do pacto constitucional, ver-se-á que também esse processo é permeado pelas nuances desse poder. Baseando-se nos princípios da reciprocidade e generalidade, os direitos humanos são instrumentalizados no sentido de justificar estruturas tidas como injustas, conferindo legitimidade às mesmas (NEVES, 2012). No entanto, devido à transversalidade do poder na sua constituição, existe em seu contornar uma área cinzenta aberta à disputa política, justamente pela sua vinculação estrita ao exercício do poder.

É assim que no Brasil a aplicação da Justiça de Transição foi permeada pela conjuntura política imbrincada da época de superação do regime militar, que por si, não se encerrava nas fronteiras brasileiras, mas sofria a influência mais geral do contexto internacional que surgia. 
Fala-se aqui do processo de debacle do bloco socialista. Nos 40 anos passados a sociedade capitalista se moldara sob a sombra de uma ameaça iminente: o avanço do socialismo. Isso levava o Estado a resguardar algumas responsabilidades sociais, como forma de bloqueio ao movimento contestatório. $O$ debate que surgia da nova configuração mundial girava em torno de outro item: a austeridade (SOUTO; NORONHA; COSTA; PEREIRA; NORONHA, 2018).

Internamente, isso arrefeceu as demandas de uma parcela da oposição à ditadura, mais ligada ao debate social (que angariava forças desde a década de 1970), com sintomas inclusive para frações de classe da burguesia que dependiam de incentivos ao investimento produtivo (a burguesia interna), fortalecendo as frações mais ligadas ao grande capital internacional, em especial o financeiro (a burguesia compradora). Isso se dá porque o eixo da austeridade se encontra na diminuição das funções estatais, em benefício da iniciativa privada. Em termos de economia dependente, essa iniciativa se articula em torno da intervenção privada externa. Do embate entre as perspectivas econômicas e sociais dessas classes e frações de classe, da luta de classes em outras palavras, nasce a contraditória pactuação política em torno da CF88, que apesar de avançar por sobre questões materiais, não garante o erigir de estruturas institucionais que permitam a adequada implementação de seus dispositivos (RIBEIRO, 2005).

O que se argumenta nesse trabalho é que esse embate não cerceou a capacidade da CF88 em versar sobre os direitos humanos em suas variadas vertentes, mas o próprio processo pelo qual se viabilizariam as estruturas para sua aplicação: a Justiça de Transição.

Essa insígnia seria carregada também pela literatura, que classificaria o caso brasileiro como:

[...] um processo de transição por transformação, levado a cabo pelo próprio regime militar autoritário, sem que a Sociedade Civil ou o Estado de Direito insurgentes fossem capazes de, efetivamente, promover uma agenda de medidas transicionais que não aquelas planejadas pelo próprio regime (ABRÃO; TORELLY, 2011, p. 473).

Desde o pacto que iniciou o fim da ditadura cívico-militar, até a criação da Comissão Nacional da Verdade em 2012, percorreu-se caminho marcado por políticas de reparação como modus operandi da justiça transicional brasileira. Essas políticas, que têm início já na própria Lei de Anistia de 1979, são estruturadas ao longo dos anos 1990 e 2000 (MEZAROBBA; BRANDÃO, 2008).

A política de reparação inaugurada pela lei $N^{\circ} 6.683 / 1979$ debruça seu enfoque sobre a seara laboral, permitindo de início a readmissão daqueles servidores desligados por motivações políticas. Com base nesse histórico, as ações reparatórias futuras dariam especial atenção ao saneamento com relação às violações no âmbito do trabalho. Advém daí a essência do Ato das Disposições Constitucionais Transitórias da CF88, que estende a reparação laboral também ao 
setor privado. Esse dispositivo, no entanto, só foi operacionalizado em 2001, através de uma Medida Provisória de FHC. Nos 13 anos que distanciaram essas medidas, edita-se a Lei $\mathrm{N}^{\circ}$ 9.140/1995, que buscou fornecer reparações aos familiares de mortos e desaparecidos durante a ditadura, que foi alimentada pelos pareceres da Comissão Especial de Mortos e Desaparecidos Políticos (CEMDP), inaugurada em 1995. Paralelamente a essa comissão, estabeleceu-se a Comissão de Anistia, responsável por averiguar desrespeitos mais gerais cometidos pelo Estado a indivíduos entre 1946 e 1988 (ABRÃO; TORELLY, 2011).

Ao deter-se diante da abrangência do escopo investigativo da Comissão de Anistia, percebe-se a dificuldade de tratar sobre o período específico da ditadura cívico-militar (19641985), incitando à inferência de que a presença dos militares na pactuação política que deu espaço à CF88 era ainda significativa.

Mas é justamente no período de transição da ditadura para o pacto democrático, entre os anos 1970 e 1980, que os direitos humanos perdem sua característica puramente legislativa e abstrata e passam a ganhar corpo no debate cotidiano dos atores políticos e com isso, tomam parte no imaginário popular (HOLLANDA, 2018). Dessa forma, sua incorporação no processo político de democratização do país teve igualmente impactos importantes, aprofundando o caráter dialético da transição democrática brasileira, uma vez que não apenas elementos constrangedores à utilização dos direitos humanos como princípio se apresentaram, mas também elementos que a impulsionavam.

Apesar disso, a justiça transicional empenhada no período posterior à derrota política do regime militar estava focada em ações de reparação, voltadas majoritariamente para o cunho laboral da questão, não entrando a fundo nas questões adjacentes dos direitos humanos no geral. No entanto, tal não equivale a afirmar que o sistema de reparação se deu apenas no campo econômico, já que fazia parte desse escopo, ainda que não de forma sistemática, ações educativas com objetivo de aprofundar o significado da memória e da verdade (ABRÃO, TORELLY, 2011). A conferência dessa maior amplitude às ações deveria ter por finalidade a restauração da confiança cívica que se rompe, em situações de exceção, entre sujeito violado, sociedade ambiente e o próprio Estado (CORREA, 2010).

Segundo Silva Filho (2018) o aprofundamento das funções da Comissão de Anistia, nesse sentido acima mencionado, se daria apenas em 2007, já no segundo mandato de Luís Inácio Lula da Silva, quando a comissão deixa seu caráter de "esquecimento" ao estabelecer a necessidade de comprovação da perseguição política, o que faz com que novos documentos venham à tona, retirando do esquecimento fatos que passavam por esse processo desde 1979. Alinhados a essa nova perspectiva, são criados projetos de cunho educativo e de 
reestabelecimento da memória, como as Caravanas da Anistia, as Clínicas do Testemunho, o Projeto Marcas da Memória e o Memorial da Anistia (Programa Brasileiro de Reparação Integral).

A visão aqui proposta é que tais iniciativas não incidiam no contexto imediato de desmantelamento das estruturas sobreviventes, na democracia, da forma de Estado ditatorial, mas buscavam atuar no campo da disputa de narrativas, item de pertinência se inserido no contexto mais amplo da disputa por hegemonia.

Uma ação mais integrada no sentido de dar vazão à Justiça de Transição no Brasil só encontraria a luz em 2012, no primeiro mandato de Dilma Rousseff, com a inauguração da Comissão Nacional da Verdade.

Uma Comissão da Verdade, de acordo com Cristina Buarque de Hollanda (2018) pode ter dois enquadramentos: um em que a justiça penal é a finalidade máxima de suas ações e outra em que se aproxima mais de uma justiça restaurativa, em que a exposição da verdade, por si, seria suficiente. Como essa experiência (de comissões da verdade) não é exclusividade do processo histórico brasileiro, ela se adaptou aos diferentes contextos políticos e institucionais de cada país (GUTMANN; THOMPSON, 2000), tendendo mais ou menos para um dos enquadramentos propostos.

A opção por uma linguagem neutra que normalmente faz uma comissão da verdade, a aproxima, como já exposto, do contexto dos direitos humanos, fazendo com elas tenham, portanto, uma função de equilíbrio entre antagonismos e de conferência de legitimidade às suas ações (HOLLANDA, 2018). Isso se torna evidente quando observado o processo na África do Sul:

O caso sul-africano é paradigmático porque mostra como é possível satisfazer o critério de legitimidade aqui referido nos níveis individual e coletivo. Mais do que isso, os sul-africanos foram capazes de atender às exigências de construção moral dos direitos humanos, pois a estrutura normativa que pautou sua transição política, incluindo aí a efetivação do "direito à verdade", não pôde ser rejeitada com razões recíproca e genericamente válidas. Todos os envolvidos com violações de direitos humanos - o que incluiu diferentes grupos políticos, até mesmo o Congresso Nacional Africano, partido de Nelson Mandela - tiveram de apresentar seus motivos e razões (NEVES, 2012, p. 178).

No Brasil, a instalação da Comissão Nacional da Verdade segue a diretriz da imparcialidade, mas uma característica própria do processo brasileiro permitiria espaço para a disputa de narrativas por vieses mais parciais: a liberdade conferida às Subcomissões da Verdade (HOLLANDA, 2018). As Subcomissões não se articulavam de forma linear o que, de acordo com a visão aqui proposta poderia se dar por duas razões: 1) Esse movimento se dá no sentido de permeabilização do debate às entidades vinculadas ao pensamento mais progressista. Dessa forma geraria acúmulos no sentido de disputa de narrativa, sem com isso pôr em xeque o delicado arranjo político que dava sustentação como liderança de governo ao 
Partido dos Trabalhadores (PT). 2) Justamente por esse arranjo político, não se logrou direcionar recursos suficientes para a pauta de forma a bem articular nacionalmente uma rede de comissões da verdade.

Sikkink e Marchesi (2015) categorizariam a Comissão Nacional da Verdade como um nítido processo de abandono do esquecimento consequente da Lei de Anistia de 1979, estabelecendo como princípio para o tempo presente o acesso a verdade sobre a ditadura. A pulverização das Subcomissões da Verdade, de forma irregular, pelo território nacional vem dar complemento à essa afirmação, vocalizando personagens ora preteridos da história nacional.

O fator desencadeante é indubitavelmente a Comissão Nacional da Verdade. Essa força motriz, diferente de gerar estruturas solidamente estatais, gera espontaneidades, absorvendo em grande medida as características de um movimento social, minimamente organizado por uma política de Estado. As interações entre as diferentes perspectivas geradas através desse movimento/política levam a acúmulos que podem no final apresentar sínteses que, em certa medida, contenham também a devida neutralidade, pois organizações com divergentes perspectivas políticas podem se movimentar para disputar as narrativas advindas dos trabalhos dessas subcomissões.

Essas movimentações, aliadas a Lei de Acesso à Informação № 12.527/2011 criam, de forma processual, um movimento dialético entre aceitação e contestação dos termos da Anistia de 1979:

\footnotetext{
A novidade foi dirigir seu esforço investigativo, incrementado pela Lei de Acesso à Informação, para esclarecer estruturas e redes da repressão, e, desse modo, investigar e compreender casos individuais de vitimação com referência ao quadro mais geral de violações do regime. Em termos formais, essa inflexão relevante não colidiu com as diretrizes de 1979: sua lei de criação mobilizou princípios de direitos humanos e reconciliação perfeitamente acomodados aos termos da anistia. Na prática, contudo, a CNV e o comissionismo tensionaram - com diferentes formas e intensidades - os discursos de reconciliação e anistia (HOLLANDA, 2018, p.6)
}

Essa passagem pode dar indicações do processo mais amplo de disputa de narrativa, ainda mais quando as Subcomissões da Verdade estariam reguladas por três ideais que Hollanda (2018) descreveria como a pedagogia da verdade (a verdade em oposição a esquecimento, tida com sentido profilático); a condição atemporal dos direitos humanos; e a simbiose entre democracia e direitos humanos. No entanto, esse processo não é livre de contradições. Ainda segundo a autora, a CNV, diferente do que fora realizado no processo sulafricano, não se dedicou à análise da cooperação entre o regime cívico-militar e a iniciativa privada. Mais uma vez absorve-se daí a necessidade de equilíbrio entre as forças constituintes do bloco no poder. 
Outro fator que poderia levar a essa consideração é o próprio discurso de Dilma Rousseff quando da instalação da CNV. Apesar do histórico da presidenta de enfrentamento ao regime, a palavra "militar" não é proferida uma única vez ao longo de mais de 20 minutos de discurso, em que se celebra a pactuação como mecanismo de superação de crises no Brasil:

[...] Ao instalar a Comissão da Verdade não nos move o revanchismo, o ódio ou o desejo de reescrever a história de uma forma diferente do que aconteceu, mas nos move a necessidade imperiosa de conhecê-la em sua plenitude, sem ocultamentos, sem camuflagens, sem vetos e sem proibições [...]Tanto quanto abomina a violência e preza soluções negociadas para as suas crises, o Brasil certamente espera que seus representantes sejam capazes de se unir em torno de objetivos comuns, ainda que não abram mão, mesmo que mantenham opiniões divergentes sobre outros temas, o que é normal na vida democrática[...] (CNV, 2012).

A instalação da CNV toma lugar dois anos após o Supremo Tribunal Federal (STF) julgar o mérito da Lei de Anistia de 1979, em 2010. Na ocasião a corte suprema brasileira reconheceu os termos da lei $N^{\circ} 6.683 / 1979$. Essa decisão vai na contramão do entendimento de que uma autoanistia (uma anistia aplicada pelos próprios violadores) viola o núcleo moral dos direitos humanos e de que nenhum poder político, nem mesmo um poder constituinte, pode exigir que os indivíduos abdiquem do direito à verdade em nome da estabilidade política e social (NEVES, 2012).

A contradição exposta entre as posições jurídicas e políticas desse período histórico leva, finalmente, à elaboração de uma questão espinhosa: qual o papel dos projetos políticos no período imediato de transição da ditadura para a democracia? A implementação do neoliberalismo teve papel catalizador para a conservação de estruturas antidemocráticas? É sobre esse questionamento que se debruça a próxima seção.

\section{O NEOLIBERALISMO E SEUS EFEITOS SOBRE A CONCRETUDE DEMOCRÁTICA}

Para analisar os efeitos sobre a democracia, da organização de um bloco no poder que implementasse no Brasil, o projeto neoliberal, é necessário compreender, ainda que de forma sintética, o processo pelo qual o neoliberalismo passou a servir como ideologia fundacional de um bloco histórico mundializado. Nesse ínterim, faz-se imprescindível o conhecimento dos dispositivos teóricos desse pensamento, principalmente naquilo que tangencia a matéria em questão: a democracia e de forma mais ampla, os direitos humanos como sua base.

Para tal tarefa, retoma-se o período do entre guerras na Europa do século XX. A recessão em que se encontravam os Estados, principalmente os europeus, colocava sob contestação preceitos básicos do liberalismo econômico, ainda mais tendo-se como plano de fundo a 
passagem do capitalismo concorrencial ${ }^{4}$ para o capitalismo monopolista ${ }^{5}$ que marcara a virada do século. A necessidade de reconstrução dos Estados não se fazia congruente com a não intervenção estatal sobre a economia, gerando contradições no cerne da teoria econômica liberal. O advento da Segunda Guerra mundial e a posterior oposição entre o bloco liderado pelos Estados Unidos (EUA) de um lado e a União Soviética (URSS) de outro, vem a consolidar esse nascente tipo de organização do capitalismo, que seria pactuado sob o Estado de Bem-estar Social. Sua tipificação se dava em torno de um Estado que garantisse o funcionamento do mercado, ainda que muitas vezes regulado por dispositivos estatais, aliado a uma atuação ativa daquele em setores tidos como básicos: saúde, educação, seguridade social, segurança pública. A partir dessa organização, o conflito entre capital e trabalho, que outrora se dera em torno do modo de produção, enfoca-se no modo de distribuição da produção. Isso só seria possível mediante uma conformação de blocos no poder que contemplassem (ainda que de formas díspares) as diversas frações da burguesia, lideradas pelas burguesias nacionais, assim como setores das classes trabalhadores organizadas (CANDIOTTO, 2012).

As diversas configurações de blocos no poder no cenário internacional, assim como as interações entre os blocos históricos conformados em torno do projeto capitalista (liderado pelos EUA) e socialista (liderado pela URSS) levam então a consolidação do próprio bloco histórico que se constituiria embasada, como propôs Candiotto (2012), pela teoria keynesiana. Segundo o autor, existia na organização econômica desse bloco, uma contradição entre os âmbitos macro e microeconômicos, que terminaria por dar base a uma nova proposta político-econômica neoliberal, fundamentada principalmente no pensamento hayekiano, dando lugar a um novo bloco histórico, o neoliberal.

Esse bloco histórico neoliberal, surgido das contradições formadas no interior do bloco histórico do Estado de bem-estar social, começa a ser constituído na década de 1970, com a crise do petróleo de 1973, passando pela experiência chilena sob a ditadura militar de Pinochet e se estruturando mundialmente a partir de ascensão de Tatcher no Reino Unido (1979) e Reagan nos Estados Unidos (1980) (CANDIOTTO, 2012). A queda da União Soviética em 1991 inicia o processo que seria denominado por Chesnais (1996) de mundialização desse bloco.

Vê-se que para Hayek (1987), teórico estruturador da ideologia desse bloco, a economia deveria estar completamente desvinculada da política, sendo orquestrada por um corpo de especialistas autônomos e permanentes, sendo esse o caminho pertinente para o fim máximo

\footnotetext{
${ }^{4}$ A livre concorrência garante a posição de hegemonia do capital industrial. É através dessa concorrência que se definem os preços, os salários e a taxa de lucro (HOBSBAWM, 2006)

5 Caracterizado pela predominância do capital fictício (financeiro), em que se combinam concentração e centralização de capital à disputa imperialista entre os Estado centrais (HILFERDING, 1985)
} 
da humanidade, a liberdade individual. Vislumbra, em suma, um minimalismo do Estado, enxergando-o como um mal, porém um mal necessário para a tarefa primordial de garantir que as liberdades individuais sejam cumpridas, o que só se daria de forma inerente à atuação livre dos mercados.

Com essa perspectiva em mente, o debate sobre direitos humanos torna-se, se não desnecessário, ao menos secundário na democracia proposta pelo neoliberalismo, uma vez que esse debate se ergue sobre elementos considerados como "adjetivações" segundo a teoria neoliberal, que pressupõe que desemprego e desigualdade são variáveis naturais e estruturais do funcionamento do livre mercado (CANDIOTTO, 2012). O debate proposto pelo campo dos direitos humanos apresenta, assim, atritos permanentes com as postulações neoliberais, pois pressupõe que um ambiente devidamente democrático seja capaz de dar resposta a tais itens, uma vez que condições matérias de reprodução da vida e emprego se categorizariam como direitos humanos, como versam, por exemplo, os artigos $22^{\circ}$ e $23^{\circ}$ da Declaração Universal dos Direitos Humanos (OHCHR, 2020).

Por outro lado, toma-se como base a perspectiva de Bobbio (1996) sobre a democracia e sua necessidade participativa através de variadas instituições da sociedade civil, vê-se mais uma vez o neoliberalismo em oposição ao sentido democrático, uma vez que segundo Perry Anderson (1995) o objetivo da ação estatal no neoliberalismo se dá sob a necessidade de fazer-se forte na capacidade de desarticular o poder dos sindicatos, na mesma medida em que seria fraco nos gastos sociais e intervenção estatal na economia. O desemprego estrutural como forma de enfraquecimento dos sindicatos, logo, vai de encontro ao princípio de democracias concretas, uma vez que, sendo eles organizações de representação de seguimentos sociais, sua desestruturação gera concentrações de poder.

Essas conceituações sobre democracia (e as práticas depreendidas delas) só são possíveis devido a não existência de um conceito universal e unívoco de democracia, o que leva Gentili (1998, p.45) a categorizar o modelo neoliberal como uma "simulação democrática" a serviço do capital.

Infere-se dessa forma que está na raiz da teoria neoliberal a defesa de uma democracia limitada, como pode-se observar nas proposições hayekianas, de que a única democracia possível seria aquela sem adjetivos, útil exclusivamente para a manutenção da paz interna e das liberdades individuais.

De acordo com as postulações neoliberais, a democracia, em seu conteúdo verdadeiro, é inalienável do mercado, no entanto, a recíproca não é verdadeira. Vê-se então, que a limitação da democracia é item essencial para a proteção do mercado, sem o qual, na concepção 
neoliberal, não existem liberdades (CANDIOTTO, 2012). Com isso é possível estabelecer laços de conexão entre o projeto político-econômico aplicado no Brasil na década de 1990, a necessidade de se bloquear mecanismos de uma Constituição que percebe a democracia de forma "adjetivada" e ampla e a insistência na não aplicação de uma Justiça de Transição, como forma de estabelecer entraves à construção de uma forma de Estado que superasse aquela estabelecida entre 1964 e 1985 e buscasse aplicar de fato uma forma democrática concreta.

O movimento de elaboração e promulgação da Constituição de 1988 buscava não apenas superar as estruturas da ditadura cívico-militar que fora vigente no país por vinte e um anos, mas também dar concretude a essa democracia através de uma regulação da dinâmica capitalista, buscando alinhar, igualmente, suas estruturas sociais e econômicas as de países de democracias consolidadas. Postulava, portanto, uma contradição aos termos de Hayek "de que, para se realizar um planejamento eficaz, a gestão econômica deve ser afastada da área política" (HAYEK, 1987, p.78) e, logo, aos imperativos neoliberais, que se consolidariam concomitantemente, à nova experiência dessa Constituição. A Constituição de 1988, então, enfrentava um desafio duplo: superar a forma de Estado ditatorial sem a possibilidade de aplicação efetiva de uma Justiça de Transição, diante dos efeitos da Lei de Anistia de 1979 e da Emenda Constitucional $N^{\circ} 26 / 1985$ e apresentando-se na contramão de um movimento global por diminuição da estrutura social do Estado (NETTO, 1999).

O projeto neoliberal se aprofunda sob as administrações de FHC, cuja governabilidade dependia, essencialmente, da flexibilização dos direitos sociais (NETTO, 1999), uma vez que o bloco no poder que lhe deu sustentação era conduzido pela burguesia compradora, que conduzia a expansão neoliberal (BERRINGER, 2014). Segundo Azevedo (1999), a crença neoliberal coloca que a flexibilização de direitos sociais seria necessária para o livre fluir das forças do mercado. Em nome, então, da modernização e da inserção no novo modo de acumulação flexível do capitalismo contemporâneo, as políticas sociais foram asfixiadas em nome da estabilidade monetária e do controle da inflação (CANDIOTTO, 2012). As formas encontradas para inviabilizálas, seriam o uso sistemático de Medidas Provisórias e Emendas Constitucionais, como meio de interditar os aspectos sociais da CF88 (CANDIOTTO, 2012), assim como o bloqueio à devida superação das estruturas antidemocráticas, ou seja, à Justiça de Transição como forma de punição dos envolvidos e não apenas reparação das vítimas.

A transformação proposta pela constituição de 1988 viu-se, em vários momentos, entravada pela própria constituição dos preceitos neoliberais. O enfraquecimento ou diminuição das estruturas de Estado possui contradições com a necessidade que se depreende da aplicação 
de Justiça de Transição, como por exemplo, alocação de pessoal e recursos para o processo investigativo, assim como para a reestruturação das instituições consequente do processo.

Esses aspectos impossibilitaram a construção efetiva de uma estrutura de validação e promoção dos direitos humanos, sociais e econômicos previstos na carta de 1988 e prolongaram seus efeitos mesmo sob novas configurações de blocos no poder, que ainda que objetivassem medidas de efetivação desses direitos e de alienação da pauta neoliberal, se viram constrangidas por reformas aplicadas nesse período (BOITO JR; BERRINGER, 2013).

Com o que fora exposto, resta então o exercício de absorver das reflexões aqui colocadas, algumas conclusões.

\section{CONCLUSÕES}

A análise do processo de transição do último "período de exceção" brasileiro, para o seu mais longo período de estabilidade democrática, sob a ótica da aplicação dos mecanismos necessários para a superação das estruturas antidemocráticas, visando a construção de instituições capazes de ter como princípio regulador os direitos humanos, é permeada pelas nuances da disputa por hegemonia. Inserem-se nesse contexto os projetos político-econômicos, a disputa de narrativas, a Justiça de Transição.

Com isso em vistas, e a partir do estudo aqui levantado, percebe-se que a "excepcionalidade continuada" se vê presente ainda que sob estruturas formalmente democráticas, devido ao processo, iniciado na Anistia de 1979, que permitiu a continuidade das estruturas construídas ao longo de 21 anos de uma forma de Estado ditatorial. A pactuação que deu origem à Constituição de 1988 se ergue sobre termos contraditórios que constrangeram o próprio poder Constituinte, tendo como base a Emenda Constitucional N²6/1985, que na prática impossibilitou a Constituinte de rever os termos da anistia.

Soma-se a isso a concomitante aplicação de um projeto econômico-político, alinhado ao bloco histórico neoliberal, que tinha por fundamentação teórica a "desadjetivação" da democracia, ou seja, o esvaziamento da capacidade da mesma em seus termos sociais, políticos e econômicos, enfocando-a na garantia do funcionamento do mercado. As alternâncias na configuração do bloco no poder acirraram a disputa da narrativa em torno do regime militar, através da consolidação de políticas de justiça transicional, que culminariam na Comissão Nacional da Verdade e suas Subcomissões, que mais pareciam garantir caráter de movimento social à pauta. A evidência, segundo Silva Filho (2018), de que o projeto neoliberal impõe entraves à aplicação de Justiça de Transição seria que um dos primeiros atos de governo após 
a deposição de Dilma Rousseff (2016) (e o realinhamento do bloco no poder em torno do neoliberalismo) seria a reestruturação da Comissão de Anistia, substituindo seus membros por outros não ligados à pauta dos direitos humanos.

Como pôde-se ver ao longo desse trabalho, uma série de medidas de cunho transicional foi tomada no Brasil, no entanto, com uma expressa aversão ao processo de responsabilização, administrativa e penal. Conjugado à ausência de reformas públicas e legais efetivas, tal situação abre espaço, tanto para a permeabilização de medidas antidemocráticas, quanto para a sistemática infração aos próprios dispositivos da Constituição que deu sentido à democracia brasileira.

\section{REFERÊNCIAS}

ABRÃO, Paulo; TORELLY, Marcelo D. O programa de reparações como eixo estruturante da justiça de transição no Brasil. In: REÁTEGUI, Félix. Justiça de Transição: manual para a américa latina. Manual para a América Latina. Brasília: Comissão de Anistia, 2011. p. 473-516.

ANDERSON, Perry. Balanço do neoliberalismo. In: SADER, E.; GENTILI, P. (Orgs.). Pósneoliberalismo: as políticas sociais e o Estado democrático. 3. ed. São Paulo: Paz e Terra, 1995.

AZEVEDO, Plauto Faraco de. Direito, justiça social e neoliberalismo. São Paulo: Ed. Revista dos Tribunais, 1999.

BERRINGER, Tatiana. Bloco no poder e política externa nos governos FHC e Lula. 2014. 223 p. Tese (doutorado) - Universidade Estadual de Campinas, Instituto de Filosofia e Ciências Humanas, Campinas, SP. Disponível em:

<http://www.repositorio.unicamp.br/handle/REPOSIP/281111> Acesso 01/04/2020

BOBBIO, Norberto. Democracia. In: SANTILLÁN, José Fernández (org.). Norberto Bobbio: el filósofo y la política. México: Fondo de Cultura Económica. pp. 229-238. 1996

BOITO JR, Armando; BERRINGER, Tatiana. BRASIL: classes sociais, neodesenvolvimentismo e política externa nos governos Lula e Dilma. Revista de Sociologia e Política, Curitiba, v. 21, n. 47, p. 31-38, set. 2013. Disponível em: <http://www.scielo.br/scielo.php?pid=S010444782013000300004\&script=sci_abstract\&tlng=pt> Acesso 01/04/2020

CANDIOTTO, Cesar. Neoliberalismo e Democracia. Princípios: Revista de Filosofia, Natal, v. 19, n. 32, p. 153-179, dez. 2012. Disponível em:

https://periodicos.ufrn.br/principios/article/view/7568/5631. Acesso: 01/04/2020

CHESNAIS, François. A Mundialização do Capital, Tradução Silvana Finzi Foá, São Paulo, Xamã, 1996.

CNV. A instalação da Comissão Nacional da Verdade. 2012. Disponível em: http://cnv.memoriasreveladas.gov.br/institucional-acesso-informacao/a-cnv/57-a-instalacao-dacomissao-nacional-da-verdade.html. Acesso: 01/04/2020. 
CORREA, Cristián. Programas de reparação pra violações em massa aos direitos humanos: aprendizados das experiências da Argentina, Chile e Peru. Revista Anisitia Política e Justiça de Transição, v. 3, p. 140-172, jan. 2010

GENTILI, Pablo. A falsificação do consenso: simulacro e imposição na reforma educacional do neoliberalismo. Petrópolis, RJ: Vozes, 1998

GOMES, Ana suelen Tossige; MATOS, Andityas Soares de Moura Costa. O estado de exceção no Brasil republicano. Direito e Práxis, Rio de Janeiro, v. 8, n. 3, p. 1760-1787, 2017. Disponível em: http://www.scielo.br/pdf/rdp/v8n3/2179-8966-rdp-8-3-1760.pdf. Acesso: $01 / 04 / 2020$

GRAMSCI, Antônio. Os Intelectuais e a Organização da Cultura. São Paulo: Círculo do Livro, 1985.

GUTMANN, Amy.; THOMPSON, Dennis. The moral foundations of truth commissions. In: ROTBERG, R.I.; THOMPSON, D. (orgs.). Truth vs. justice: the morality of truth commissions. Princeton: Princeton University Press. 2000

HAYEK, Friedrich August. O caminho da servidão. 4. ed. Rio de Janeiro: Expressão e Cultura: Instituto Liberal, 1987.

HILFERDING, Rudolf. O capital financeiro. São Paulo: Nova Cultural, 1985.

HOBSBAWN, Eric. A era das revoluções. Tradução: Maria Tereza Lopes Teixeira e Marcos Penchel. Rio de Janeiro: Editora Paz e Terra, 2006.

HOLLANDA, Cristina. Direitos Humanos e Democracia: A experiência das comissões da verdade no Brasil. Revista Brasileira de Ciências Sociais, Rio de Janeiro, v. 33, n. 96, p.118, 1 out. 2018. FapUNIFESP (SciELO). Disponível em:

http://www.scielo.br/pdf/rbcsoc/v33n96/0102-6909-rbcsoc-33-96-e339610.pdf. Acesso:

01/04/2020

MEZAROBBA, Glenda; BRANDÃO, Gildo Marçal. O preço do esquecimento: as reparações pagas às vítimas do regime militar (uma comparação entre Brasil, Argentina e Chile). 2008. Universidade de São Paulo, São Paulo, 2008. Disponível em:

https://tesis.museodelamemoria.cl/Tesis_PDF/tesis\%20glendamezarobba.pdf. Acesso:

01/04/2020

MOREIRA, André Mendes. Anistia. Enciclopédia jurídica da PUC-SP. Celso Fernandes Campilongo, Alvaro de Azevedo Gonzaga e André Luiz Freire (coords.). Tomo: Direito Tributário. Paulo de Barros Carvalho, Maria Leonor Leite Vieira, Robson Maia Lins (coord. de tomo). 1. ed. São Paulo: Pontifícia Universidade Católica de São Paulo, 2017. Disponível em: https://enciclopediajuridica.pucsp.br/verbete/267/edicao-1/anistia. Acesso: 05/05/2020

MOYN, Samuel. The last utopia. Cambridge: Harvard University Press, 2010. Disponível em: http://docenti.unimc.it/benedetta.barbisan/teaching/2017/17581/files/the-last-utopia-humanrights-in-history. Acesso 01/04/2020

NETTO, José Paulo. FHC e a política social: um desastre para as massas trabalhadoras. In: LESBAUPIN, I. (Org.). O desmonte da nação: balanço do governo FHC. Petrópolis, RJ: Vozes, 1999. 
NEVES, Raphael. Uma Comissão da Verdade no Brasil? Desafios e perspectivas para integrar direitos humanos e democracia. Lua Nova: Revista de Cultura e Política, São Paulo, n. 86, p.155-186, 2012. FapUNIFESP (SciELO). Disponível em: http://www.scielo.br/scielo.php?pid=S010264452012000200006\&script=sci_abstract\&tlng=pt. Acesso: 01/04/2020

OHCHR. Declaração Universal dos Direitos Humanos. 2020. Disponível em: https://www.ohchr.org/EN/UDHR/Pages/Language.aspx?LangID=por. Acesso: 01/04/2020.

POULANTZAS, Nicos. Poder político e classes sociais. São Paulo: Martins Fontes, 1977.

RIBEIRO, Paulo Roberto Rios. Estado e luta de classes na Constituição Federal de 1988. in: Jornada Internacional de Políticas Públicas, 2., 2005, São Luís. Anais [...]. São Luís: Programa de Pós-Graduação em Políticas Públicas Ufma, 2005. p. 1-10. Disponível em:

http://www.joinpp.ufma.br/jornadas/joinppll/pagina_PGPP/Trabalhos2/Paulo_Roberto_Ribeiro30 0.pdf. Acesso: 01/04/2020.

SALES, Raquel Bento de. Justiça de Transição Como Instrumento de Viabilização da Qualidade da Democracia e Redemocratização dos Sistemas Políticos: comparação entre: Brasil, Argentina e Chile. In: IX Seminário Internacional de Direitos Humanos da UFPB, 2016, João Pessoa.

SCHINKE, Vanessa Dorneles. Judiciário e autoritarismo: regime autoritário (1964-1985), democracia e permanências. Rio de Janeiro: Lumen Juris, 2016. Disponível em: http://repositorio.pucrs.br/dspace/handle/10923/7837. Acesso 01/04/2020

SCHMITT, Carl. Teoría de la constitución. Tradução de Francisco Ayala. Madrid: Alianza, 1996. Disponível em: https://www.lustracionjuridica.com/producto/teoria-de-la-constitucion-carlschmitt-pdf/. Acesso em: 01/04/2020

SIKKINK, Kathryn; MARCHESI, Bridget. Nothing but the truth: Brazil's truth commission looks back. Foreign Affairs, v. 26, fev. 2015. Disponível em:

https://www.foreignaffairs.com/articles/south-america/2015-02-26/nothing-truth. Acesso: $01 / 04 / 2020$

SILVA FILHO, José Carlos Moreira da. Justiça de Transição e Usos Políticos do Poder Judiciário no Brasil em 2016: um Golpe de Estado Institucional? Direito e Práxis, Rio de Janeiro, v. 9, n. 3, p.1284-1312, 2018. Disponível em: https://www.epublicacoes.uerj.br/index.php/revistaceaju/article/view/31488. Acesso: 01/04/2020. 
SOUTO, Lucia Regina Florentino; NORONHA, Gustavo Souto; COSTA, Ana Maria; PEREIRA, Telma Ruth; NORONHA, José Carvalho de. Civilização ou Barbárie. Saúde Debate, Rio de Janeiro, v. 42, n. 3, p. 125-144, nov. 2018. Disponível em:

http://www.scielo.br/scielo.php?script=sci_abstract\&pid=S0103-

11042018000700125\&lng=en\&nrm=iso\&tlng=pt. Acesso: 01/04/2020.

TEITEL, Ruti. Genealogia da justiça transicional. In: REÁTEGUI, Félix. Justiça de Transição:

Manual para América Latina. Brasília: Comissão de Anistia, 2011. p. 135-170. 